\title{
Obesity and Male Infertility
}

\author{
Elif Gelenli Dolanbay \\ Istanbul Medeniyet University, Faculty of Medicine Department of Histology and Embryology \\ Civilizations Istanbul University North Campus D Block Faculty of Medicine, Department of \\ Histology and Embryology, D-100 highway Side road Unalan Uskudar Istanbul Turkey 34700 \\ E-mail: egelenli@gmail.com/elif.dolanbay@medeniyet.edu.tr
}

\begin{abstract}
Obesity is defined as the presence of excess amount of body fat tissue. Infertility is defined as the inability to conceive after a year of unprotected sexual intercourse and affects about $15 \%$ of the couples. Male fertility factor is a single factor in approximately $20 \%$ of infertile couples, while $30 \%$ and $40 \%$ have both male and female factors. Thus the male factor is present in approximately half of the pairs. An increase in male infertility is observed in parallel with decreasing sperm quality worldwide. The increase in obesity prevalence has led researchers to investigate the relationship between obesity and male infertility. The mechanisms by which paternal obesity affects sperm or embryo are still not fully described. It has been observed that the process of conception has been prolonged in couples with obese male partners. The aim of this review is to evaluate the relationship between male infertility and obesity.
\end{abstract}

Keywords: Infertility, obesity, male.

DOI: $10.7176 / \mathrm{JSTR} / 5-4-24$

\section{Obezite ve Erkek İnfertilitesi}

\begin{abstract}
Özet
Obezite, vücutta aşırı miktarda yağ dokusunun bulunması olarak tanımlanmaktadır. İnfertilite, bir yılın sonunda korunmasız cinsel ilişkiye rağmen gebe kalınamaması olarak tanımlanır ve çiftlerin yaklaşık \% 15'ini etkilemektedir. İnfertil çiftlerin yaklaşık \%20'sinde erkek fertilite faktörü tek başına bir sebep iken diğer \%30 ile \%40'lık kısmında hem erkek hem de kadın faktörü bulunmaktadır. Böylece erkek faktörü çiftlerin yaklaşık yarısında bulunmaktadır. Dünya genelinde azalan sperm kalitesine paralel olarak erkek infertilitesinde bir artış görülmektedir. Obezite prevalansındaki artış, araştırmacıları erkeklerdeki obezitenin infertilite ile ilişkisini araştırmaya yöneltmiştir. Paternal obezitenin spermi veya embriyoyu etkilediği mekanizmalar halen tam olarak açıklanamıştır. Obez erkek partneri olan çiftlerde gebe kalma sürecinin uzadığı görülmüştür. Bu derlemedeki amaç erkek infertilitesi ile obezite arasındaki ilişkinin değerlendirilmesidir.
\end{abstract}

Anahtar Kelimeler: İnfertilite, obezite, erkek

\section{Giriş}

Kadınlara göre obez erkeklerde fertilite; obezitenin steroidogenez üzerindeki önemli etkisi olduğu düşünülmesine rağmen çok az çalışılmıştır. Epidemiyolojik çalışmalar eksiktir. Bununla birlikte, spermatogenez ve fertilite masif şekilde obez olan olgularda azalabilir (Strain ve diğ 1982).

Erkeklerde obezite, hormon tablosunu değiştirip, spermatogenezi azaltarak fertiliteyi etkileyebilir. Spermatogenez, puberteden ölüme kadar süren oldukça karmaşık bir olaydır ve hipotalamus, hipofiz bezleri ve testislerde bulunan Leydig ve Sertoli hücreleri tarafindan düzenlenir. Testislerin işlevini esas olarak hipofizden salınan Bunlar folikül stimüle edici hormon (FSH) ve luteinizan hormon (LH) düzenler. LH, Leydig hücrelerine etki ederek bu hücrelerden testosteron üretilmesini sağlarken; FSH spermatogenezi başlatır. Gonadotropin serbestleştirici hormon (GnRH), FSH ve LH'nın salınımını kontrol eder. LH, testislerdeki Leydig hücrelerini stimüle eder ve testosteron salınımını sağlar. FSH Sertoli hücreleri üzerinde etkilidir ve adenilat siklazı uyararak cAMP düzeylerini arttırır. Seks hormon bağlayıcı globulin (SHBG) sentezini ve salgısını da FSH uyarır. FSH sertoli hücrelerini uyararak başta SHBG ve inhibin olmak üzere onlarca molekülün salgılanmasına yol açarak spermatogenezin başlatılması ve devam ettirilmesinde rol oynamaktadır (De Kretser ve diğ. 2000) Erkeklerde artan VKI'nin azalmış serum seks hormonları, SHBG, testosteron, inhibin B ve FSH düzeyleri ile ilişkisi 
olduğu bulunmuştur (Pauli ve diğ.2008). VKİ ile serum testosteron ve SHBG'nın negatif bir ilişkili olduğu bir metaanalizde bildirilmiştir ( Mac Donald ve diğ. 2010). VKI'i yüksek erkeklerde fazla sentezlenen insülinin hepatik globülini inhibe ettiğine inanılmaktadır (Pasquali ve diğ.2007). Obez erkekte vücut ağırlığının artmasıyla toplam ve serbest testosteron kan derişimleri ilerleyici şekilde azalır ve bu azalmaya cinsiyet hormonlarını bağlayan globin derişiminde bir azalma eşlik eder. Dolaşımdaki androstenedion ve dihidrotestosteron düzeyleri genelde ya normaldir ya da hafifçe azalmıştır. Obezitede 5 alfa redüktaz aktivitesi üzerinden testosteron metabolizmasındaki değişiklik de görülebilir ancak halen tartışmalıdır (Pasquali 2006). Erkeklerde abdominal yağ dağılımının testosteron düzeyleri üzerinde ileri negatif bir etkisi olabilir (Pasquali 2006, Wajchenberg ve diğ. 2000).

İnhibin B, erkeklerde spermatogenezi göstermede en önemli belirteçlerden biri olarak görüldüğünden, obez erkeklerde sperm kalitesini göstermede kullanılabileceği hakkında fikir sürülmiștür. İnhibin B sertoli hücrelerinin normal olup olmadığının göstergesi olarak da görülebilir (Pauli ve diğ.2009, Pierik ve diğ. 2003). Genel görüş olarak obez kişilerin normal bireylerden daha düşük inhibin B seviyelerine sahip olduklarına inanılır. Normal ağırlıktaki bireylere göre bu oran \%25-32 daha düşük olarak karşımıza çıkar (Aggerholm ve diğ. 2008). Sertoli hücreleri tarafindan desteklendiğinden dolayı, sertoli hücrelerinin bulunmaması sperm sayısının azlığına yol açmaktadır. Yaşları 18-24 yıl arasında değişen 72 erkek olguda VKİ ile inhibin B arasındaki ilişkiyi incelenen çalışmada hipotalamo-hipofizer-gonad aksında görevli hormon olan inhibin B'nin obezitenin artması ile azaldığı görülmüş ve bu azalma normal bireylere göre obezlerde \%26 olarak bildirilmiştir (Winters ve diğ.2010).

Erkek infertilitesinde sperm parametreleri önemli ölçütlerdir. Sağlıklı gebelikler için spermin moleküler yapısının ve içeriğginin önem taşıdığı düşünülmektedir. Başarılı fertilizasyon ve normal embriyonik gelişim için Sperm DNA bütünlüğü önemlidir ve DNA hasarlı spermle başarılı gebelikler arasında negatif bir ilişki olduğunu gösteren çalışmalar bulunmaktadır (Kumar ve diğ. 2012, Thomson ve diğ. 2011 ).

Obez erkeklerde DNA kırılma oranlarının arttığı gösterilmiştir (Pacey ve diğ. 2010). VKİ artması ile DNA kırılmalarının arttığı; motilitenin ise azaldığını bildirmişlerdir (Sallmén diğ. 2006). Bu durumun kötü kaliteli spermatogenez ve dolayısı ile azalmış sperm sayısı ve azalmış motilite ile ilişkili olabileceği belirtilmiştir (Kort ve diğ. 2006).

Pek çok genetik faktörün erkek infertilitesine neden olduğu bilinmektedir. Genetik defektlerle bilinen bazı obezite sendromları hem obeziteden hem de spermatogenezden sorumlu tek gen işlev kaybıyla ilişkili olarak özellikle erkek infertilitesi ile bağlantılı bulunmuştur. (örneğin Alström sendromunda Alms 1 geni) (Mah ve diğ.2010, Arsov ve diğ.2006). Benzer olarak kromozomal bölgedeki (15q11-q13) birkaç gen de hem defektif spermatogeneze hem obeziteye (örneğin Prader-Willi sendromu ve Angelman sendromları) neden olmaktadır (Buiting ve diğ. 2003). Sigara içimi gibi pek çok yaşam stili etkisi sperm fonksiyonunu bozar ve bu nedenle bu tür çalışmaların analizlerini zorlaştırmaktadır. Bugüne kadar obezitenin fertilite üzerine etkisini direk araştıran kontrollü hayvan modeli çalışmalarının azlığ da bu konudaki çelişkilere yol açmaktadır.

Erkek obezitesinde "subfertilite" durumunun arttığını gösteren çalışmalar mevcuttur. Bu durum birçok nedenle olabilir. Bu durum gerçek işlevsel bir hipogonadotropik hipogonadizm durumunu yansıtan hipotestosteronemik durumla kısmen açıklanabilir. Bu tarz durumlarda oligospermi de görülebilir (Pasquali 2006). Subfertil çiftlerin değerlendirildiği bir çalş̧mada, fazla kilolu erkeklerin semen analizinde ve immotil sperm oranının arttığı progresif motilitenin belirgin bir biçimde azaldığı gösterilmiştir (Hammiche ve diğ. 2012)

Obezite ile sperm konsantrasyonu, total motil sperm sayısı ve ejakülat volümü ile arasında anlamlı düzeyde negatif korelasyon saptanmıştır. Santral obezitenin bir göstergesi olan bel çevresinin $(>102 \mathrm{~cm})$ total motil sperm ve sperm konsantrasyonu sayısı ile anlamlı düzeyde ters ilişkili olduğu belirtilmiştir. Ancak artan VKİ ile semen analizi sonuçlarındaki değişiklikleri açıklayan bir mekanizma_henzü saptanamamıştır (Hammiche ve diğ. 2012)

Pek çok çalş̧mada özellikle VKI $>30 \mathrm{~kg} / \mathrm{m} 2$ olduğunda sperm motilitesinin etkilendiği bildirilmektedir. Buna rağmen bazı çalışmalarda obezitenin sperm motilitesine etki etmediği bildirilmiştir (Magnusdottir ve diğ. 2005).

Sperm sayısı ve VKİ arasındaki ilişkinin incelendiği çalışmalarda sonuçların kısmen çelişkili olduğu görülse de VKİ ile morfoloji arasındaki ilişkinin incelenmesinde daha net sonuçların elde edildiği anlaşılmaktadır. Geniş serili çalışmalar başta olmak üzere pek çok araştırmada obezite ile sperm morfolojisi arasında ilişki olmadığı bildirilmektedir (Hammoud ve diğ. 2008, Chavarro diğ.2010, Pauli ve diğ. 2009, Jensen TK ve diğ.2004). Kü̧̈ük serili çalışmalarda karmaşık sonuçların olduğu görülmektedir. Obezler ile normal bireylerdeki sperm morfolojisinin karşılaştııılması farklı çalışmalarda farklı yöntemlerin kullanılması nedeni ile zor olmaktadır. Sınırlı sayıda çalışma olsa da semen volümü ve obezite ilişkisinin incelendiği anlaşılmaktadır. Bu konu ile ilgili çalışmalarda Chavarro ve arkadaşlarının çalışması hariç beşinde VKİ ile semen volümü arasında anlamlı ilişki bulunmamıştır 
(Magnusdottir EV ve diğ.2010, Chavarro diğ.2010, Pauli ve diğ. 2009, Jensen TK ve diğ.2004, Qin DD ve diğ. 2007).

Leptin reseptörleri insan testislerinde yaygın olarak eksprese edilir (Moschos ve Chan 2002). Testosterona uzun süreli maruz bırakılan insan yağ hücreleri in vitro olarak leptin ekspresyonunu baskılar (Moschos ve Chan 2002) ve erkek kemiricilerin kültürü yapılmış Leydig hücrelerinde, LH ve hCG ile uyarılmış androjen üretimini muhtemelen 17-20 liyaz aktivitesiyle ilgili mekanizmalar üzerinden negatif şekilde etkilediği gösterilmiştir (Caprio ve diğ. 1999). Hipogonadizmi olan erkeklerde leptin düzeyleri düşüktür ancak testosteron replasman tedavisiyle normale döner (Jockenhovel ve diğ.1997). Obez erkeklerde yapılan çalışmalarda leptin düzeyleri ile bazal ve hCG ile uyarılmış testosteron düzeyleri arasında anlamlı negatif ilişkiler olduğu gösterilmiştir (Isidori ve diğ. 1999). Bu durumda, dolaşımdaki leptin fazlasının obez erkeklerde testosteron düzeylerinin azalmasına katkıda bulunduğu teorisi desteklenir.

Bununla birlikte, klinik çalışmalarda yaygınlığın oldukça yüksek olduğunun belirtilmesine rağmen obezitede ereksiyon işlev bozukluğu yaygınlığına yönelik çalışma yapılmamıştır (Chung ve diğ. 1999, Shiri ve diğ. 2004). İlginç olarak, ereksiyon işlev bozukluğu kilo kaybı ile tersine çevrilebilmektedir (Esposito ve diğ. 2004). Yapılan bir çalışmada 40-70 yaşlar arasındaki büyük bir erkek kohortu incelenmiştir ve ereksiyon işlev bozukluğunun geneldeki yaygınlı̆ı $\% 17$ olduğu gözlenmiş ancak; VKI değerleri $30 \mathrm{~kg} / \mathrm{m} 2$ 'nin üzerindeki olgularda \% 45'e yükselmiştir. Sağlı Profesyonelleri İzlem Çalışmasında, VKİ $28.7 \mathrm{~kg} / \mathrm{m} 2$ değerinin üzerinde olan erkeklerde ereksiyon işlev bozukluğu riskinin VKİ normal $(<25 \mathrm{~kg} / \mathrm{m} 2)$ olanlardan \%30 daha yüksek olduğu gösterilmiştir (Bacon ve diğ. 2003). Ereksiyon işlev bozukluğu erkeklerde infertilitenin çok sık ancak dolaylı bir nedeni olduğundan klinik altyapıda göz önünde bulundurulmalıdır. Ereksiyon işlev bozukluğu ve tip 2 DM arasındaki kuvvetli ilişkiyi gösteren ve ereksiyon işlev bozukluğunun kalp ve damar hastalı̆̆ açısından bir risk faktörü olduğunu gösteren bulgularla bu durum iyice vurgulanmaktadır (Russell ve diğ. 2004).

\section{Paternal obezite ve klinik gebelik verileri:}

Fazla kilolu veya obez erkek partnere sahip subfertil/ infertil çiftlerde artan paternal VKI'nin gebelik ve canlı doğum oranları gibi klinik gebelik verileri üzerine negatif etkileri güncel çalışmalar ile gösterilmiştir. Geniş bir örnekleme sahip epidemiyolojik bir çalı̧̧mada, paternal obezite ile infertilite arasında anlamlı lineer bir korelasyon olduğu gösterilmiştir (Sallmén ve diğ. 2006). Prospektif, 114 çifte ait 172 yardımlı üreme siklusunun incelendiği bir çalışmada ICSI uygulanan çiftlerde; paternal obezite ile siklus başına ve transfer edilen embryo başına düşen canlı doğum oranları arasında anlamlı negatif bir ilişki saptanmıştır (Colaci ve diğ. 2012).

Sonuç olarak obezite ile erkek infertilitesi arasında bağlantının olup olmadığı halen tartışmalıdır. Bu yüzden deneysel araştırmalar ve gebelik oranlarını da içeren geniş prospektif randomize klinik çalı̧̧malarla bu bulguların desteklenmesi gerekmektedir.

\section{References}

Aggerholm AS, Thulstrup AM, Toft G, Ramlau-Hansen CH, Bonde JP.(2008). "Is overweight a risk factorfor reduced semen quality and altered serum sex hormone profile." Fertil Steril,90:619-26.

Arsov T, Silva DG, O’Bryan MK, Sainsbury A, Lee NJ, Kennedy C, Manji SS, Nelms K, Liu C, Vinuesa CG, de Kretser DM, Goodnow CC, Petrovsky N.(2006)." Fat aussie--a new Alström syndrome mouse showing a critical role for ALMS1 in obesity, diabetes, and spermatogenesis." Mol Endocrinol, 20(7):1610-1622.

Bacon CG, Mittleman MA, Kawachi I, et al. (2003)."Sexual function in men older than 50 years of age: results from the Health Professional Followup Study.” Ann Intern Med, 139:161-168.

Buiting K, Gross S, Lich C, Gillessen-Kaesbach G, el-Maarri O, Horsthemke B. (2003). "Epimutations in Prader-Willi and Angelman syndromes: a molecular study of 136 patients with an imprinting defect." Am J Hum Genet, 72(3):571-577.

Caprio M, Isidori AM, Carta AR, et al.(2009)." Expression of functional leptin receptors in rodent Leydig cells." Endocrinology, 140:4939-4947.

Chavarro JE, Toth TL, Wright DL, Meeker JD, Hauser R. (2010)."Body mass index in relation to semen quality, sperm DNA integrity, and serum reproductive hormone levels among men 
attending an infertility clinic.” Fertil Steril, 93: 2222-31. [CrossRef]

Chung Ws, Sohn JH, Park YY. (1999).’'Is obesity an underlying factor in erectiledys function.” Eur Urol, 36:68-70.

Colaci DS, Afeiche M, Gaskins AJ, Wright DL, Toth TL, Tanrikut C, Hauser R, Chavarro JE.(2012).” Men's body mass index in relation to embryo quality and clinical outcomes in couples undergoing in vitro fertilization." Fertil Steril, 98(5):1193-9.

De Kretser DM, Meihardt A, Meehan T, Phillips DJ, O’Bryan MK, Loveland KA.(2000).” The roles of inhibin related peptids in gonadal function." Mol Cell Endocrinol, 161(1-2) :43-46.

Esposito K, Giugliano F, Di Palo C, et al. (2004). Effect of lifestyle changes on erectile dysfunction in obese men: a randomized controlled trial. JAMA, 291:2978-2984.

Hammiche F, Laven JS, Twigt JM, Boellaard WP, Steegers EA, Steegers-Theunissen RP. (2012). "Body mass index and central adiposity are associated with sperm quality in men of subfertile couples.” Hum Reprod. Aug;27(8):2365-2372.

Hammoud AO, Gibson M, Peterson CM, Meikle AW, Carrell DT. (2008).” Impact of male obesity oninfertility: a critical review of the current literature." Fertil Steril. 90:897-904.

Isidori AM, Caprio M, Strollo F, et al.(1999)." Leptin and androgens in male obesity: evidence for leptin contribution to reduced androgen levels. "J Clin Endocrinol Metab, 84:3673-3680.

Jensen TK, Andersson AM, Jørgensen N, Andersen AG, Carlsen E, Petersen JH, Skakkebaek NE. (2004)." Body mass index in relation to semen quality and reproductive hormones among 1,558 Obezite ve Erkek İnfertilitesi / Obesity and Male Infertility men.” Fertil Steril, 82:863-70.

Jockenhovel F, BlumWF, Vogel E, et al. (1997).”Testosterone substitution normalizes elevated serum leptin levels in hypogonadal men." J Clin Endocrinol Metab, 82:2510-2513.

Kort HI, Massey JB, Elsner CW, Mitchell-Leef D, Shapiro DB, Witt MA, Roudebush WE. (2006)."'Impac of body mass index values on sperm quantity and quality." J Androl, 27:450-2

Kumar K, Deka D, Singh A, Mitra DK, Vanitha BR, Dada R.(2012).”Reproductive value of DNA integrity analysis in idiopathic recurrent pregnancy loss follwing spontaneous conception." J Asist Reprod Genet, 29(9): 861-867.

Mac Donald AA, Herbison GP, Showell M, Farquhar CM.(2010)." The impact of body mass index on semen parameters and reproductive hormones in human males: a systematic review with metaanalysis.” Hum Reprod Update, 6(3): 293-311

Magnusdottir EV, Thorsteinsson T, Thorsteinsdottir S, Heimisdottir M, Olafsdottir K. (2005).”Persistent organochlorines, sedentary occupation, obesity and human male subfertility." Hum Reprod, 20:208-15.

Mah PM, Wittert GA. (2010).”Obesity and testicular function.“ Mol Cell Endocrinol. 316(2): 180186.

Moschos S, Chan JL, Mantzoros CS. (2002).’Leptin and reproduction: a review.” Fertil Steril, $77: 433-444$.

Pacey AA.(2010)."Environmental and lifestyle factors associated with sperm DNA damage." HumFertil. 13:189-93. 
Pasquali R.(2006).” Androgens and obesity: fact and perspectives.” Fertil Steril, 85:1319-1340.

Pauli EM, Legro RS, Demers LM, Kunselman AR, Dodson WC, Lee PA. (2009).”Diminished paternity and gonadal function with increasing obesity in men."Fertil $\mathrm{S}$ clinic. Fertil Steril,92:1016-7.

Pauli EM, LegroRS, Demers LM, Kunselman AR, Dodson WC, Lee PA. (2008).”Diminished paternity and gonadal function with increasing obesity in men." Fertil Steril, 90(2): 346-351)

Pierik FH, Burdorf A, de Jong FH, Weber RF.(2003).” Inhibin B: a novel marker of spermatogenesis."Ann Med, 35:12-20.

Qin DD, Yuan W, Zhou WJ, Cui YQ, Wu JQ, Gao ES. (2007) .Do reproductive hormones explain the association between body mass index and semen quality. Asian J Androl. 9:827-34.

Russell ST, Khandheria BK, Nehra A.(2004)." Erectile dysfunction and cardiovascular disease." Mayo Clin Proc, 79:782-794.

Sallmén M, Sandler DP, Hoppin JA, Blair A, Baird DD. (2006). "Reduced fertility among overweight and obese men." Epidemiology, 17(5):520-3.

Shiri R, Koshimaki J, Hakama M, et al. (2004).”Effect of lifestyle factors on incidence of erectile dysfunction.” Int J Impot Res, 16:389-394.

Strain GW, Zumoff B, Kream J, et al.(1982)."Mild hypogonadotropic hypogonadism in obese men." Metabolism, 31:871-875.

Thomson LK, Zieschang JA, Clark AM. (2011).”Oxidative deoxyribonucleic acid damage in sperm has a negative impact on clinical pregnancy rate in intrauterine insemination but not intracytoplasmic sperm injection cycles." Fertil Steril. 96(4):843-847

Winters SJ, Wang C, Abdelrahaman E, Hadeed V, Dyky MA, Brufsky A. (2010).”Inhibin-B levels in healthy young adult men and prepubertal boys: is obesity the cause for the contemporary de-cline in sperm count because of fewer Sertoli cells.” Int J Food Sci Nutr, 61:713-21.

Wajchenberg BL.(2000).”Subcutaneous and visceral adipose tissue: their relation to the metabolic syndrome." Endocr Rev, 21:697-738. 